$\xi_{\mathrm{P}}=$

\title{
Football Player Decision Support System Baghdad-City as a Case Study
}

\author{
Ban Salman $^{1,}$ Nada M. Alhakkak ${ }^{1}$ and Mustafa Musa Jaber ${ }^{2,3}$ \\ ${ }^{1}$ Computer Science Department - Baghdad College for Economic Science University \\ ${ }^{2}$ Faculty of Civil and Environmental Engineering, Universiti Tun Hussein Onn Malaysia, 86400, Johor, Malaysia. \\ ${ }^{3}$ Nabu Research Academies, Baghdad, Iraq
}

\begin{abstract}
Decision support system (DSS) is an area of information systems (IS) discipline which focuses on supporting decision-making. DSS includes personal decision support systems, executive information systems, online analytical processing systems, data warehousing, business intelligence, and group support systems. This paper introduced the implementation of a DSS related to football players with a case study.
\end{abstract}

Keywords: Decision support system (DSS), information systems (IS), football players.

\section{Introduction}

Every day, people are getting more and more involved in adopting new technologies, which provides them with new ways to communicate, participate, study, investigate and precede with research on given concepts. Information and Communication Technology (ICT) has gone through innovations and every aspect in every day's life of people around the world has changed as a coincidence to the changes of society. This transformation affects all aspects in the way people think, work and live [1].

Oliver [2] referred that ICT has become commonplace entities in everything relates to life and living [2].

The subject of using modern technologies in the decision support becomes an interesting topic for a large number of Information System (IS) researchers.

Decision Supports Systems (DSS) are computer-based systems which are characterized as interactive systems, used to help decision makers utilize data and models to solve unstructured problems. They process the knowledge and at the same time represent knowledge in many ways that allow decision making to be more creative, productive, innovative, and/or reputable [3].

They may be considered as tools that are used by organizations, mangers, stakeholders and decision makers to support the activities of their decision making and enhances them [4].

The best team selection of any sport is always about requirement of management in different domains. Choosing a team player for a specific sports, like football, is not a simple task to do as it goes with a variety of objectives and criteria to decide who are the most suitable players to be chosen among many candidates.

Coaching staff, managers, club stakeholders and maybe other related organizations could be a recognizable entities which are considered to be responsible of building a successful team [5].
The traditional team selection process is a time consuming, difficult and maybe confusable due to manual procedure and personal judgments; which may lead to a much undesired results. These personal judgments and constraints can be translated into software for better and quick solution.

One of the most important criteria/ factors is to identify the skills that every player has so as to have a clear vision which guides to a correct decision in selecting/ choosing such suitable players to play for the team among many candidates [5].

The scientific bases have been used recently within sport era; especially for team sports such as football, basketball and so on. This includes many aspects and has approved its positive influences in leading teams and clubs towards building a good team heading for winning.

Until now most of DSS are developed and implemented for business sector depending on the company/organization perspectives, still there are few done within the area of sport.

In this paper we are proposing a decision support system to choose a player for a football team "Football Player Decision Support System"

(FPDSS).

The system should be able to choose the appropriate football player(s) among many candidate players depending on special criteria that was chosen within consultations of football coaches. The system is easy to be used as it is designed for people who are not professional with computers. Using the system will enable any interested coach who has multiple choices of players to choose the suitable player according to scientific approach.

\section{Motivation of Study}

The process of selecting the suitable player(s) for any sport team for sports such as football, basketball, or any other sport that is a team 
player sport is a very complex decision to make [6]. The usually manual team selection process may have many drawbacks such as personal liking and disliking, personal grudges between team selection committee and players and external pressures (social, political etc.).

Recently, DSS has been successfully applied to many decisionmaking problems in many disciplines [7]. They are getting the interest from many researchers as well as business stockholders in many domains to help users taking important decisions [8].

\section{Objectives of the Study}

The primary objectives of this paper are:

$\square$ Identify the required criteria for designing the Football Player Decision Support System (FPDSS).

$\square$ Design and implement a Football Player Decision Support System (FPDSS) that could be used by coaches or athletic clubs owner and other stakeholders to select the appropriate player(s) electronically depending on scientific criteria.

\section{Decision Supports Systems (DSSs)}

According to Tripathi [9], (DSSs) are computer-based information systems designed in a way that helps people; mostly managers to select one of the many alternative solutions to a problem. It is a problem of choice among several alternatives. DSS includes the process of building alternatives or options including a search for opportunities for deciding a decision [9].

In an interactive, flexible, useful manner a DSS utilizes decision rules, models and model base with the use of appropriate Database Management System DBMS and a decision maker's own insights to implement decisions in solving problems that could be difficult to be solved otherwise.

\subsection{Components of DSSs [10].}

Three essential components of DSSs

1. Database Management System (DBMS): Serving as a data bank for the DSS, it stores large quantities of data that are associated to the categories of problems for which the DSS has been designed for in the first place and provides rational data structures with which the users will interact with.

2. Model-Base Management System (MBMS): MBMS has a major purpose in DSS, which is to transform data from the DBMS into information that is useful in the decision making operation. It should be capable also of assisting the user in the model building.

3. Dialog Generation and Management System (DGMS): The interactive interfaces which should be designed as an easy-to-use interface to assess the system's users. They should provide interaction with the model, such as gaining insight and recommendations from it. The primary responsibility of a DGMS is to enhance the ability of the system user to utilize and benefit from the DSS [10].

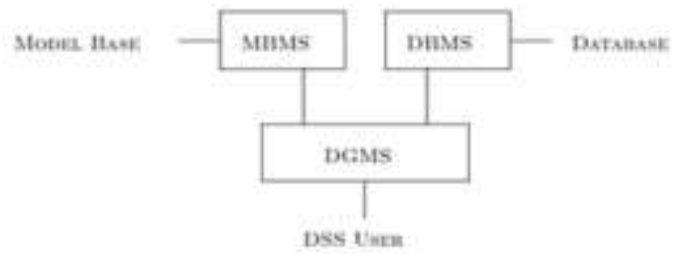

Fig. 1: The architecture of DSSs (after Saga, Ref. [10])

\section{Literature Review}

Even though DSSs are mainly designed and developed for business sector depending on the company/organization perspectives or stakeholders objectives and needs, still there are some DSSs which were developed for sport era.

Noreen et al. [15] developed a DSS to take a decision about outdoor sports should take place or not according to the weather and field conditions.

A study to improve athletes' performance by using DSS with the use of Multi-Agent system for the table tennis players was carried by Xin and Pei [18] to analyze the psychological structure for players and scientifically strength the psychological adjustment for them. A research was conducted by Zhen et al. [19] to develop a DSS for athletes' training in a two way model which is based on Bayesian Network.

Bencheng and $\mathrm{Xu}$ [20] applied a DD model which employed serial data, data mining technique, and time of ball passing and possession to provide a feasible road for football players and coach in establishing better system to overcome the other team's strategy by studying football match pattern.

Whereas, Yu et al. [17] did a study about DSS in providing a given sport team a better performance by recognizing the sports' competition Yu et al. [17].

While, Kent and Keith [16] developed a DSS program that can produce several schedule versions for Canadian Football League instead of manual creation method of league schedule.

Then, another research work that contribute to a strategy solution in football was done by Febianto [21], where Analytical Hierarchy Process (AHP) is used as a method to determine the ideal position for a player in football team.

\section{Method}

For software process methodologies, the traditional life cycle methodology is based on a structured step-by-step approach to develop systems [11]. This methodology is a fixed sequence of steps that force the developer to finish each step before development can continue to the next step [12].

In contrast to the waterfall model, the Unified Process (UP) is an iterative and incremental Model. For UP, the design process is based on iterations which either address different aspects of the design process or move the design forward, which is the incremental aspect of the model. The UP is also a case-driven; as it is known where use cases are used to help identify the primary requirements of the system. For this paper, we saw that the UP model is suitable for developing the proposed system. 6.1 UP

\subsection{Life Cycle Phases [13]}

The UP is composed of four distinct phases. According to B. Grady, C. Robert, J. Newkirk [14], the four phases of UP as resented in Figure 3, focus on different aspects of the design process. They are Inception, Elaboration, Construction and Transition. Below is a brief description for these phases.

1 Inception: In this phase the scope of the project is defined and the business case for the system is developed. In this phase also, the feasibility of the system to be built is established.

For this work the awareness of the problem began when identifying the difficulties and confections related to decision makers whom are responsible about football players' selection; especially when many choices are available (players) with nearly same abilities. 


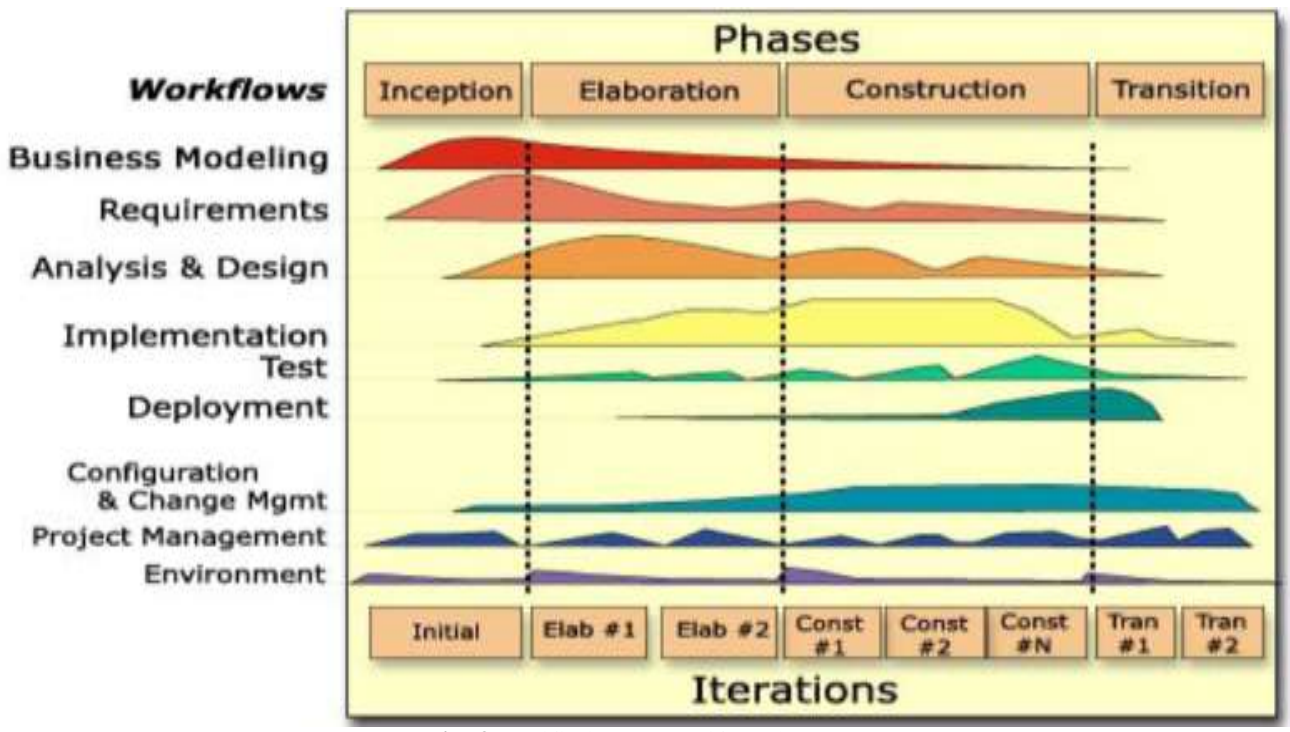

Fig. 3: Unified Process Lifecycle [13]

2- Elaboration: In this phase functional requirements of the system are captured.

A literature overview was conducted to study similar and related work. Some decision support systems have been practiced around the world related to sport field.

Also, interviews were held with football coaches to extract most important factors which we referred to as requirements they depend on when choosing suitable player(s) for football team.

3- Construction: This phase concentrates on completing the analysis of the system, performing the majority of the design and the implementation of the system. That is, it essentially builds the product. Analysis is completed and design phase has begun depending on extracted requirements from last phase. Coding programs to develop the system are done at this stage.

4- Transition: The transition phase moves the system into the user's environment. This involves activities such as deploying the system and maintaining it. The system is delivered to football club managers to be tested in the real environment with data.

UP creates a system that is easily extensible, promotes software reuse and intuitively understandable from component based architecture [14]. By its iterative and incremental nature, the UP design helps to reduce the project risk, allows great customer feedback and gives help to developers by verifying software quality.

\section{Design Section}

For developing this system, a database was created which contains important information about players who are candidate to be selected by coaches or other stakeholders. A database management system was built and the system was developed by using Visual Basic net. Figure 4 shows the main system's interface.

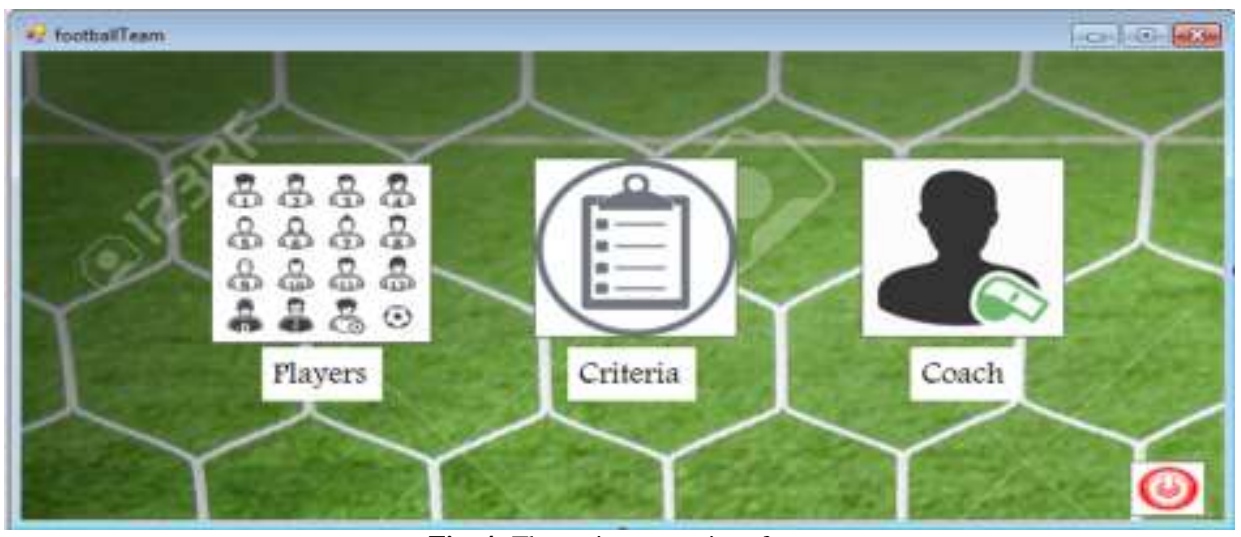

Fig. 4: The main system interface

The candidate player for the scope of this system should be with the category of age between (12-18) years ; the youth football category players.

\subsection{The Criteria Used to Evaluate the Applicant (Figure 5)}

The weight was given for each caliber as follows:

1. Player's experience: The former player's experience is given a weight of maximum 20 points. This is if he has a good experience in playing football previously in other athletic clubs , the player will get less than 20 points according to the coach/interviewer opinion.

2. Previous injuries: Maximum 20 points the player can get if he hasn't any previous injuries. These points are decreased 
according to injuries and their permanent/ temporary effect on the player.

3. Chronic diseases: If the player does not have any chronic illness, he gets 20 points, otherwise he will get less points.
4. Player's jogging Speed: If the fitness and a good jogging speed in the football field he will get 20 points and these points decreased according to the player's fitness.

5. Fitness: General player's fitness.

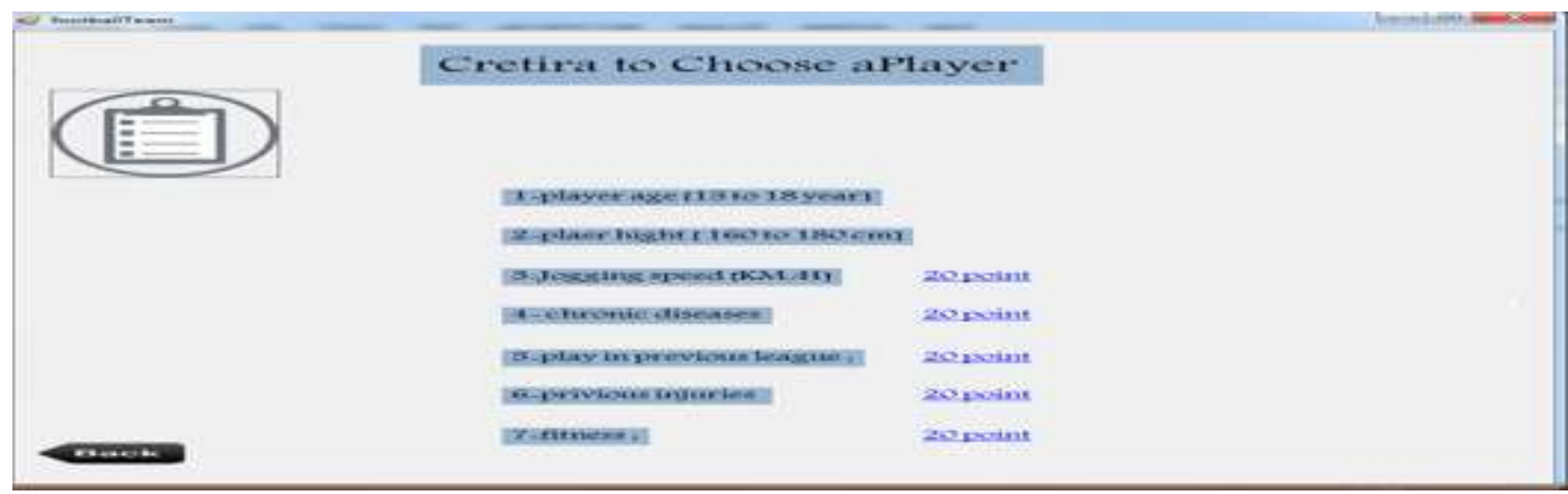

Fig. 5: Player's Criteria Interface

\subsection{Coach Interface (Figure 6)}

Through this interface, the coach enters to the system to manage it.

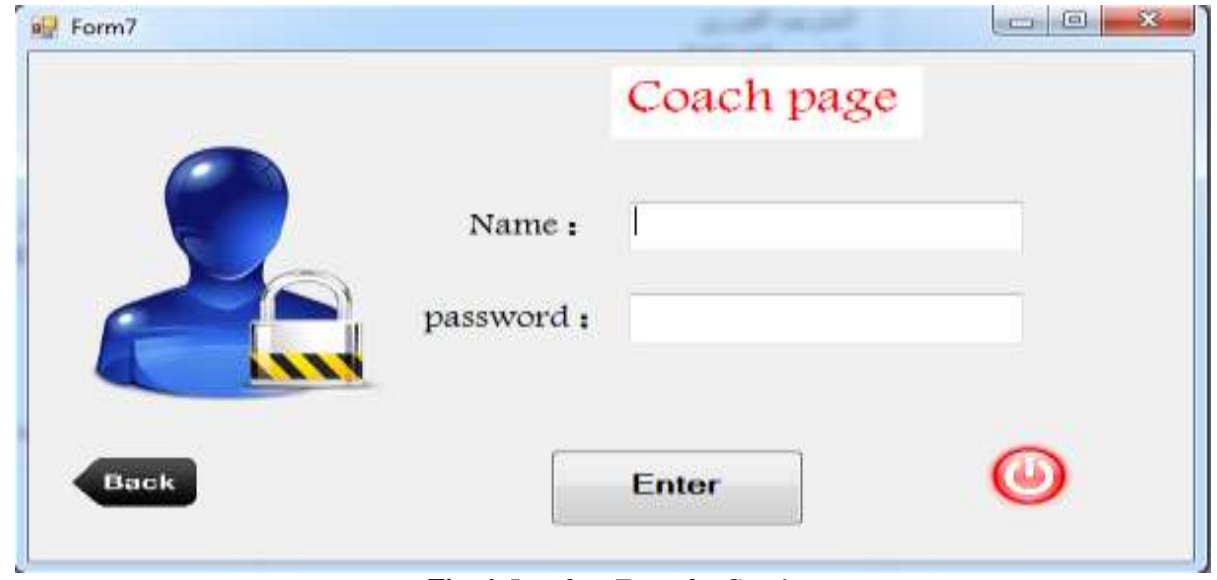

Fig. 6: Interface Entry for Coach

Catch's interface has three choices that a coach can interact with the system within them; input players information; player's criteria; and the calculated results. Figure 7 shows these choices.

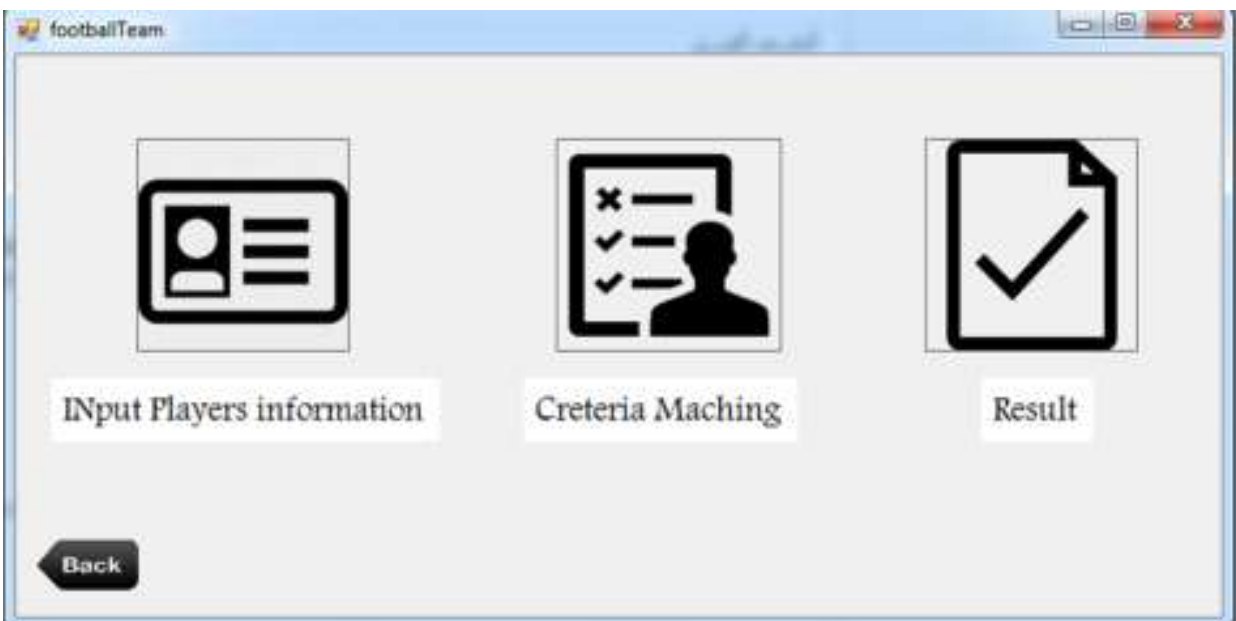

Fig. 7: Football Team Interface 


\subsection{Player Information}

All candidate players' data is filled by the coach who is responsible of this mission as was described earlier as 20 points as a maximized points that could be given for each of necessary criteria as shown in
Figure 8. Data includes: player's name, age, height, player's experience, fitness, chronic diseases, previous injurers, and the player's jogging.

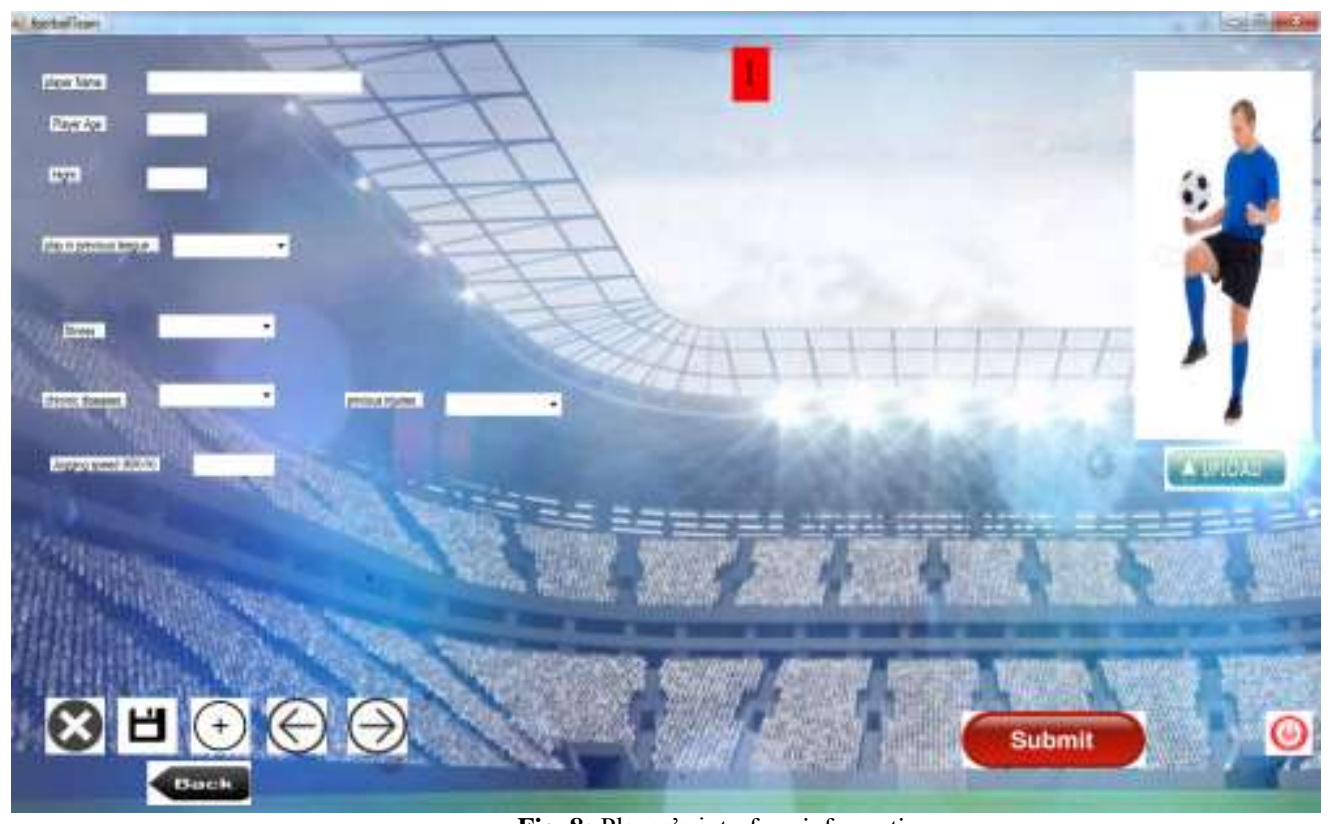

Fig. 8: Player's interface information

\subsection{Player's Information Interface}

and the score is calculated out of 100. As shown in figure 9.

Here, the players' information is displayed by coach, where the player gets all the points according to the criteria entered earlier

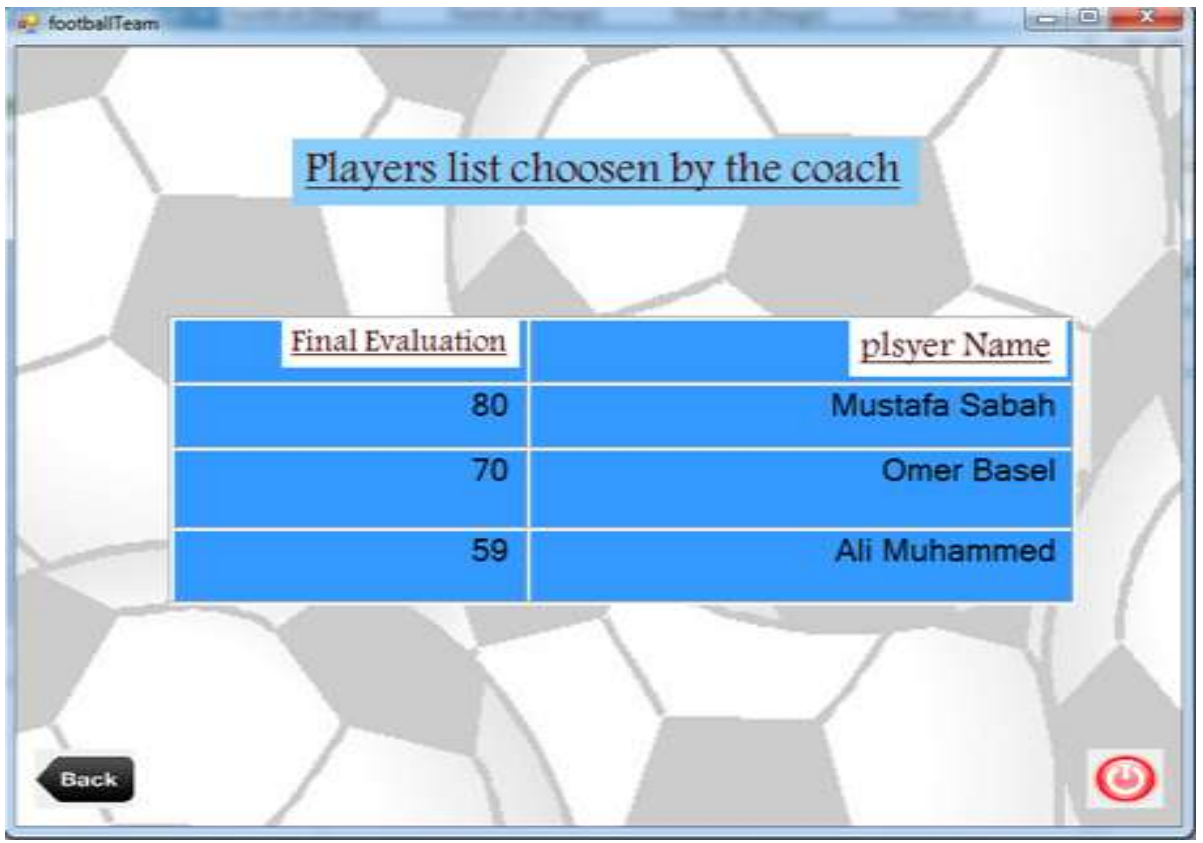

Fig 9: Player's Information Interface

\subsection{Results' Interface}

The recommender players are displayed to the coach in descending order according to their gained points they acquire earlier through the previous steps. Figure 10 shows these results as a final report for the whole work. 


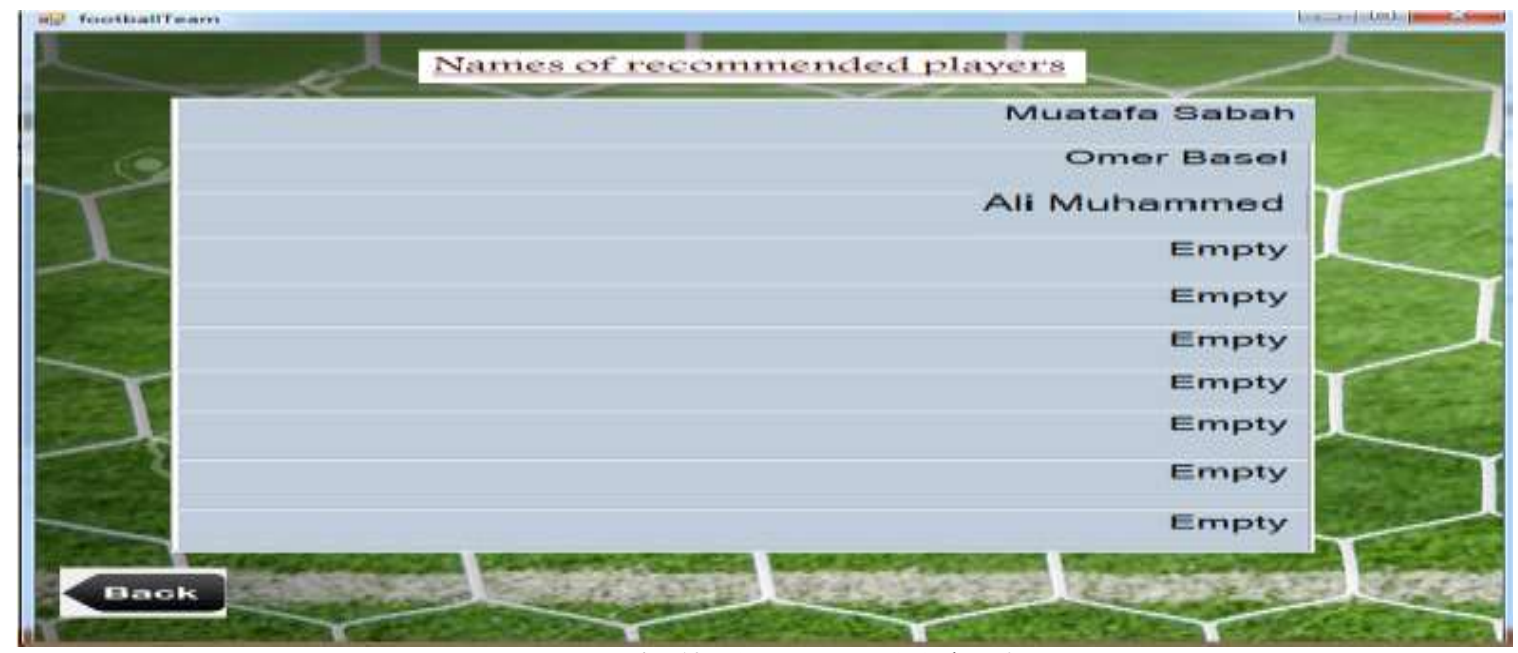

Fig. 10: The recommended Player's

\section{Conclusion and Future Work}

DSS is an important field of study and implementation of IS. This paper presented an implantation on DSS system for football players that helps the coaches for better decision between multiple players depending on special criteria with weight for each factor or criteria. The final gained points could give a hand for the coach or/and other involved stakeholders to choose the appropriate football players in a team or club. The system was implemented to be easy to use by any unprofessional person with little learning. When a reasonable amount of information is fed to system the system will depend of special kind of logic thinking to get the results presented in a report called "player's recommended interface".

For future work we intend to optimize our system to be intelligent as an expert system with the help of neural network or genetic algorithm ideas.

\section{References}

[1] M.Grabe \& C.Grabe, "Integrating technology for meaningful learning “,(5th ed.). Boston, MA: Houghton Mifflin, 2007.

[2] R.Oliver, "The role of ICT in higher education for the 21 st century: ICT as a change agent for education", 2002.

[3] M. H. Ali, M. F. Zolkipli, M. M. Jaber, and M. A. Mohammed, "Intrusion detection system based on machine learning in cloud computing," J. Eng. Appl. Sci., vol. 12, no. 16, 2017.

[4] M. H. Ali, M. F. Zolkipli, M. A. Mohammed, and M. M. Jaber, "Enhance of extreme learning machine-genetic algorithm hybrid based on intrusion detection system," J. Eng. Appl. Sci., vol. 12, no. 16, 2017.

[5] William A. Young II. "A Team-Compatibility Decision Support System to Model the NFL Knapsack Problem: An Introduction to HEART". A dissertation presented to the faculty of the Russ College of Engineering and Technology of Ohio University In partial fulfillment of the requirements for the degree Doctor of Philosophy. 2010

[6] S. M. Aqil Burney, N. Mahmood, K., Rizwan, U. Amjad. "A Generic Approach for Team Selection in Multi-player Games using Genetic Algorithm". International Journal of Computer Applications (0975 8887) Volume 40-No.17, February 2012. 2012.

A. Kardan, \& H. Sadeghi. "A Decision Support System for Course Offering in Online Higher Education Institutes", International Journal of Computational Intelligence Systems, 6(5), 928-942, 2013.

[7] PewInternet. "Teens and technology: youth are leading the transition to a fully wired and mobile nation".
[8] K. P. Tripathi, "Decision Support System is a tool for making Better Decisions in the Organization", / Indian Journal of Computer Science and Engineering (IJCSE), VOLUME 2 ISSUE 1 FEBRUARY-MARCH 2011. 2011

[9] M. Hassan, A. Fuad, M. A. Mohammed, and M. M. Jaber, "Follow up System for Directorate of Scholarship and Cultural Relations in Iraq," in International Conference on Computer, Communication, and Control Technology, 2014, no. I4ct, pp. 182-187.

[10] M. B. Alazzam, A. S. H. Basari, A. S. Sibghatullah, M. R. Ramli, M. M. Jaber, and M. H. Naim, "Pilot study of EHRs acceptance in Jordan hospitals by UTAUT2," J. Theor. Appl. Inf. Technol., 2016.

[11] B. Berg, "A framework for deciding how to pick the right methodology," URL http://csc-studentweb. lrc. edu/swp/Berg/articles/UNC-C\% 20Methodology\% 20decisions\% 20v8. doc, Abruf am, vol. 5, 2009.

[12] P. Kruchten, "What is Rational Unified Process?", The Rational Edge http://www.therationaledge.com/content/jan_01/f_rup_pk.html Accessed 2/2/2005, 2005

[13] B. Grady, C. Robert, J. Newkirk, "Object Oriented Analysis and Design with Applications", 2 edition, Addison Wesley Longman, 1998.

Noreen, M. Asim, K. Memoona, and S. H. K. Malek, Journal of Computing, 3(9), 79-84.2011

[14] J. K. Kent and A. W. Keith, "A Decision Support System for Scheduling the Canadian Football League", CORS Bulletin 45(1), 2527.2011

[15] L. Yu, P. Ling, and H. Zhang, "Study on the Decision Support System of Techniques and Tactics in Net Sports and the Application in Beijing Olympic Games", 2010 Second WRI Global Congress on Intelligent Systems.2010

[16] X. H. Gong and P. L. Ling, "Discussion on Psychological Decision Support System of Table Tennis Players Based on Multi-agent System", World Congress on Computer Science and Information Engineering. 2009.

[17] Z. Wei, F. Liu, A. Wei and X. Cui, "Fencing Training Decision Support System Based on Bayesian

[18] Network," International Conference on Computational Intelligence and Software Engineering .2009.

[19] B. Chai and X. Xu, "A Novel Decision Support Model to Discover the Interesting Pattern in Football

[20] Match," Sixth International Conference on Fuzzy Systems and Knowledge Discovery.2009.

[21] Febianto, Decision Support System for Ideal Placement of Players Position Strategy in Football Formation (Unikom, Bandung, 2010).2010 